\title{
Deriving Stress Limits for Fatigue Design with a Consideration of the Manufacturing Process Influence
}

\author{
Matthias Hell ${ }^{1}$ and Rainer Wagener ${ }^{1}$ \\ ${ }^{1}$ Fraunhofer-Institut fur Betriebsfestigkeit und Systemzuverlassigkeit LBF
}

February 18, 2022

\begin{abstract}
The material behaviour of forged components is subjected to an intensive influence of the manufacturing process. The local logarithmic strain as well as the cooling conditions may influence the cyclic stress-strain behaviour as well as the fatigue behaviour of the material. For a reliable lightweight design of components, those effects have to be considered already during early product development stages, because the definition of the component geometry will already imply process related limitations regarding the achievable local material propeties. A combination between a process simulation and a strain-based fatigue life estimation, including a customized testing strategy, allows a consideration of the manufacturing process influence as well as an implementation of statistical and mechanical size effects and improves the quality of the fatigue assessment and the reliability of numerically derived stress limits for component design compared to the state of the art.
\end{abstract}

Title:

Deriving Stress Limits for Fatigue Design with a Consideration of the Manufacturing Process Influence Authors Names and Affiliations:

Matthias Hell ${ }^{*}$

Rainer Wagener ${ }^{\mathrm{a}}$

${ }^{a}$ Fraunhofer Institute for Structural Durability and System Reliability LBF, Darmstadt, Germany

${ }^{*}$ Corresponding author.

Tel. +49176207107 79

E-mail address: matthiashell@t-online.de

\section{Abstract}

The material behaviour of forged components is subjected to an intensive influence of the manufacturing process. The local logarithmic strain as well as the cooling conditions may influence the cyclic stress-strain behaviour as well as the fatigue behaviour of the material. For a reliable lightweight design of components, those effects have to be considered already during early product development stages, because the definition of the component geometry will already imply process related limitations regarding the achievable local material propeties. A combination between a process simulation and a strain-based fatigue life estimation, including a customized testing strategy, allows a consideration of the manufacturing process influence as well as an implementation of statistical and mechanical size effects and improves the quality of the fatigue assessment and the reliability of numerically derived stress limits for component design compared to the state of the art. 


\section{Keywords}

\section{Forged Steel Components}

\section{Statistical Size Effects}

\section{Cyclic material behavior}

\section{Fatigue Life Assessment}

\section{Forging Process}

\section{Precipitation Hardening Steel}

\section{Introduction}

Forging steels offer many advantages compared to other manufacturing processes. Due to the processing of the material a considerable proportion of defects from the initial casting are reduced. At the same time, the specific microstructure of the material and the strengthening mechanisms due to recrystallization and work hardening improve the cyclic material behaviour and affect the stress-strain relation and a strain-live relation. Quenching, tempering and a huge variety of post treatments like case or surface rolling may be used to further increase the cyclic performance of the component. In order to reduce energy consumption and $\mathrm{CO}_{2}$ footprints different new steel grades in the group of precipitation hardening steels ${ }^{1,2}$ or air hardening ductile steels ${ }^{3}$ have been developed, which increase also the process stability and enable a lightweight optimization for safety relevant components. For engineers during design and optimization cycles, reliable design limits have to be available and may be derived using a digital twin, including the load assumption, process simulations, which reflect the manufacturing process from raw material to finished product, and methods to assess the fatigue life with sufficient accuracy and practicable effort. For the parametrization of the digital twin, relevant influencing factors on the material behaviour, referring either to the manufacturing process or the loading conditions should be assessd using specimens containing material states equivalent to the microstructural modifications along the process route. Coupled with the process simulation, the required specimens may either be extracted from existing components, if all process parameters are known, or generated by physical process simulations (deformation, heat treatment).

Except cases where the loads have been measured during service of comparable parts, the load assumption during the design phase is usually vague. It is therefore necessary to provide a methodology which accounts for elastic loading, which is induced by regular service loads, as well as elasto-plastic loading, occurring during misuse and being intensified at local stress concentrations, which are sometimes not entirely avoidable due to functional or package issues. With respect to the local component related material behaviour and the microstructure, the load-time function causes a constant modification and damage, which accumulates until the damage is macroscopically visible. ${ }^{4}$ For an efficient product design, which increases material utilization while preserving reliability and durability of the component, these effects have to be captured at a macrsocopic and therefore practically assessable scale by experimentation, in-service observations and a numerical fatigue approach. In order to transfer the results of experimental campaigns, service inspections and measurements to numerical design methods, different fatigue approaches have been proposed. Widely acknowleged and commonly used are approaches on basis of the nominal stress or equivalent elastic and therefore theoretical local stresses. Those methods lack the ability to capture influences of local plasticity explicitly and use correctional factors as, for example, the notch support factor, in order to account for the impact of the componente geometry and stress concentrations on the fatigue life. Although the parameters are experimentally derived by testing on notched and un-notched specimens, the transferability to a geometrically different component is limited. In order to estimate component fatigue lifes accurately with nominal stress approaches, a broad empirical basis is needed, which is usually generated by large and expensive testing campaigns. The main advantage of the nominal stress approach and equivalent approaches with linear elastic material behaviour is still the reduced numerical effort regarding finite element simulations, which makes it suitable especially for component design with a large number of design iterations. 
For forged components, strain-based fatigue approaches have distinct advantages. ${ }^{5}$ They feature an elastoplastic material model, which may be defined and parametrized arbitrarily complex, accounting for possible transient and creep effects in the local strain response to the external loading. The quality of the fatigue assessment depends to a large extent on the accurate estimation of the local stress-strain state with respect to amplitudes and mean values. For topologically optimized components with irregular shape, usually nonlinear finite element simulations will be required in order to assess the local stress response to an external loading. For simple geometries also the Neuber rule may be applied. The main disadvantage of the strainbased approaches is the necessity, to calculate each load reversal in case of variable amplitude loading with elasto-plastic loads. This may entail an enormous effort for large components with a huge number of relevant stress concentrations. Although certain simplifications allow a fatigue estimation with reduced numerical effort $^{6}$, the correct description of the component related material behaviour is still the key requirement to be achieved prior to any fatigue life assessment.

With respect to the experimental and numerical implementation of the process influence on the localized material behaviour, a process simulation is included in the fatigue design algorithm. Although the the presented studies focus on steel materials, especially precipitation hardening ferritic-pearlitic steels and heat-treatable steels, e.g. AISI 4140, the fatigue algorithm is also applicable to other steels or aluminium materials or additively manufactured structures. ${ }^{6,7,8}$

\section{Influencing factors on the component related material behaviour}

The component related material behaviour under service load-time functions is the product of continuously changing local material states due to dislocation movement, thermal activation and environmental conditions, as, for example, hydrogen exposure. Manufacturing induced defects or specific microstructures, which can be found in forged, welded or additively manufactured components may either prolongue or diminish the durability. Gradients in the microstructure always cause gradients in the local material behaviour and may be additionally superimposed by gradient stress-strain states as result of the component geometry, external loads and boundary conditions and the stress-strain relation. With respect to the local strain response to an external loading and the continuous change of the stress-strain behaviour under cyclic loading, calculating the strain response by finite element analyses requires a closed-loop description of the cylic material behaviour, accounting for the influence of accumulated damage on the material behaviour. If a sufficient methodology is available for capturing the manufacturing influences by process simulation, the accuracy of the experimental and numerical estimation of material properties will be improved by starting with the raw material. Fig. 1 presents an overview of significant influences on the material and fatigue behaviour which have to be considered exerpimentally and numerically. Especially for forged components, the consideration of the manufacturing process plays a major role for interpreting experimental and numerical fatigue assessment results and improving the quality of the numerical approach for practical purposes.

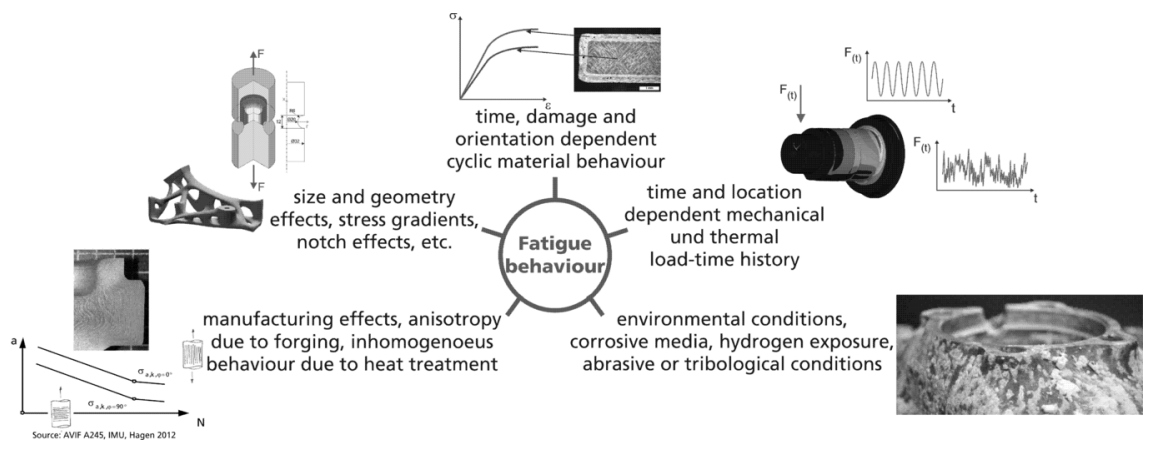

Fig. 1. Significant influences on the fatigue behaviour

A consideration of the relevant influencing factors may significantly improve the reliability of the fatigue life estimation but requires transfer methods for the mathematical description of the governing mechanisms 
and an experimental derivation of the associated material parameters. In order to be able to generate a testing strategy it is necessary, to assess possible influences of the manufacturing process, the geometrical design and the loading conditions preferably by a finite element simulations. For forged components in technically relevant dimensions, the manufacturing usually causes inhomogenieties of the microstructure, the quasistatic and the cyclic material properties, e.g. the stress-strain relation, which may be related to the local logarithmic strain or the cooling rate. The cyclically alternating local stress-strain state controls the damage contribution over time, which is a result of the external loading and the component geometry. For forged components, the manufacturing process will not only cause a time and damage dependent, locally inhomogenoues material behaviour, but also change the distribution and the morphology of flaws in the microstructur. The shape, distribution and orientation of manganese sulphides in low carbon steels may cause an anisotropy of the fatigue strength, causing a reduction of the fatigue strength between 10 and $50 \%$ if the principal stress acts perpendicular to the medial axis in longitudinal direction of the manganese sulphides. ${ }^{10}$ Directly linked to the distribution of defects in the material volume, the size effects describe the dependency between the fatigue strength of a component and the extension of the highly stressed volume in the component. Environmental conditions complete the main influences on the fatigue strength, which have to be considered already during early product development stages. Due to the complex nature of the subject, it is not possible to discuss environmental effects in this paper.

\subsection{Time and orientation dependent material behaviour}

\subsubsection{Transient stress-strain behaviour}

The transient material behaviour includes cyclic hardening or softening ${ }^{18,19}$ and, depending on the load ratio and the boundary conditions of the cyclic deformation, also cyclic ratchetting and mean stress relaxation or creep. For components in service, those cyclic effects may also be superimposed by static creep or relaxation. Transient effects have been widely acknowledged and discussed, for example in ${ }^{11,12,13,14,15,16,17}$. When calculating the local stress-strain behaviour ab initio, these effects will have a significant influence on the local stress-strain response and the damage contribution of each load cycle.

Fig. 2 illustrates the cyclical material behaviour of a 42CrMo4 (AISI 4140) heat treatable steel and a precipitation hardening ferritic-pearlitic steel 30MnVS6+Ti (EN 1.1301). The stress response to the constant amplitude loading shows a cyclic stabilization for the EN 1.1301 but a continuously transient behaviour for strain loads above $0,18 \%$ total strain for the $42 \mathrm{CrMo} 4$.

The heat-treatable steel $42 \mathrm{CrMo} 4$ (AISI 4140) shows a very strong cyclic softening for a strain amplitude $\varepsilon_{\mathrm{a}}=0,8 \%$ during the first 10 cycles, see Figure $2-1$.b, which is likely to be related to a martensite transformation, being triggered with loads above the yield limit. If the load magnitude is reduced $\left(\varepsilon_{\mathrm{a}}=0,4 \%, \varepsilon_{\mathrm{a}}=0,3 \%\right)$, the material responds to the cyclic loading with an initial hardening and a continuous softening until the crack initiation $\left(\mathrm{N}=\mathrm{N}_{\mathrm{i}}\right)$ after the initial hardening phase, Figure 2 - 1.a. For loads below the 0,2\%-yield limit, the cyclic material behaviour stabilizes and does not exhibit any significant transient effects. The common assumption of a cyclically stabilized material behaviour at half of the number of cycles to crack initiation has to be questioned with respect to the material modelling ant the accuracy of the Finite Element analysis of local stress-strain state.

The precipitation hardening ferritic-pearlitic steel 30MnVS6+Ti (EN 1.1301), Figure $2-2 . \mathrm{b}$, also shows a slight cyclical hardening during the first ten load cycles. In contrast to the $42 \mathrm{CrMo} 4$, the cyclic hardening does not depend on the load magnitude. The stress-strain behaviour also stabilizes during the cyclic loading, Figure $2-2$.a, showing only a small decline of the stress response to the continuous strain cycling until the crack initiation phase $\left(\mathrm{N}=\mathrm{N}_{\mathrm{i}}\right)$. For this material, the assumption of a cyclically stabilized stress-strain behaviour and the definition of a purely kinematic material model, will yield sufficiently accurate results during the FE analysis. 

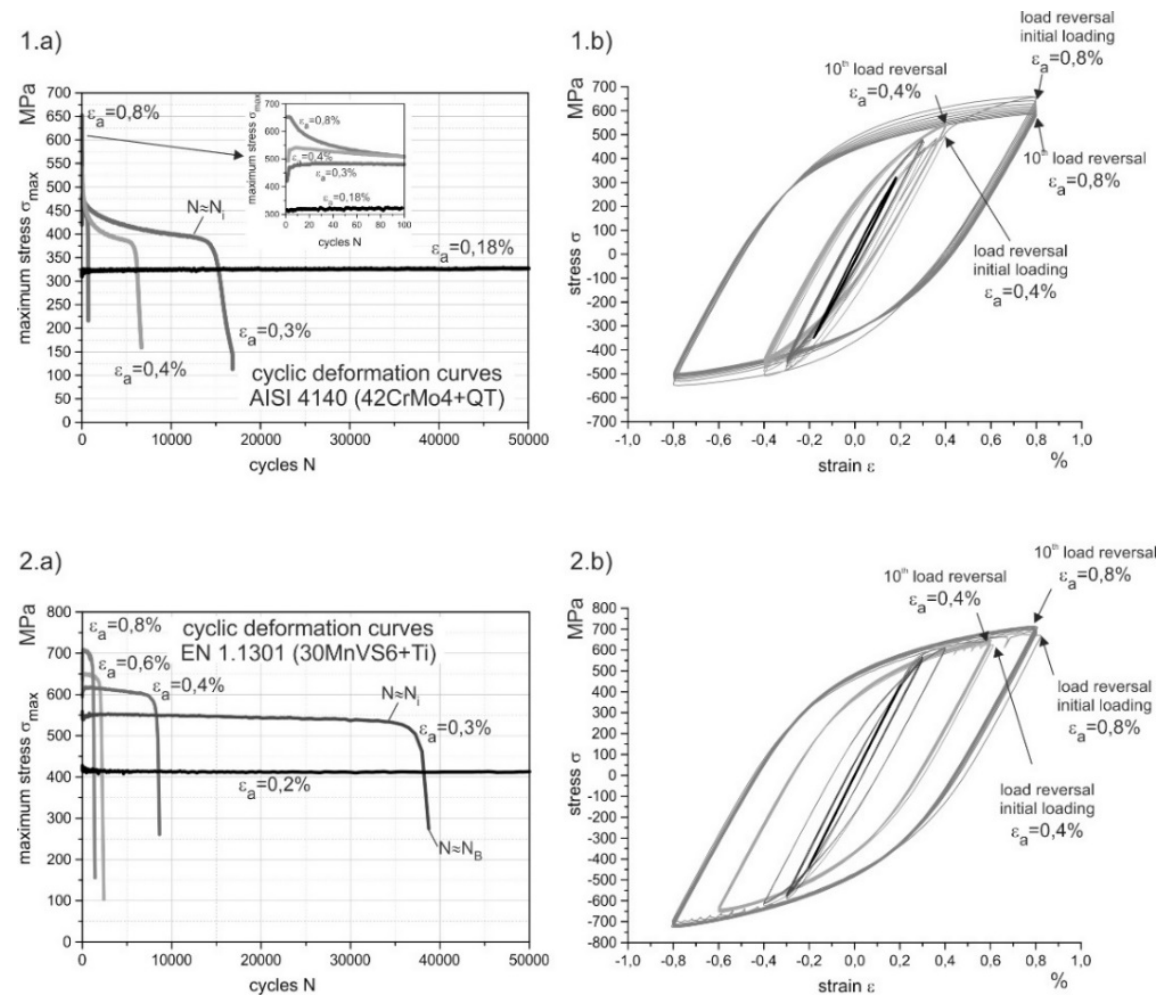

Fig. 2. Cyclic softening stress-strain behaviour of a AISI 4140 (42CrMo4+QT) and cyclically stable stressstrain behaviour with initial hardening of an EN 1.1301 (30MnVS6+Ti)

\subsubsection{Influences of the load-time history on the stress-strain behaviour}

The cyclic stress-strain behaviour is governed by continuous microstructural changes in the dislocation structur, causing also a constantly increasing degradation of the material ${ }^{18,19,20,21}$. Depending on the microstructural properties, for example the stacking fault energy, the arrangement of precipitations or interstitials, the dislocation and slip mechanisms during the cyclic loading differ significantly. While the dislocation and slip mechanisms can be validated by TEM investigations and also modelled mathematically, an upscaling of the microscale material behaviour for the evaluation of the behaviour of macroscopically large structures requires a detailed knowledge about the microstructural composition and the statistical distribution of microscale behaviour over the entire component volume, as well as enormous computing capacities. From a more practical point of view, some of the microstructural effects will also be visible at a macroscopic scale ${ }^{20}$ during the fatigue testing of the bulk material.

A cumulative effect of the dislocation movement, which is also visible during fatigue testing with constant amplitude straining and incremental step testing, is the influence of the slip behaviour on the cyclic stressstrain behaviour. Two different types of slip behaviour may be distinguished, which are directly linked to the generation of specific dislocation structures and the localization of strains within the material volume, see Fig. 4. The planar and the wavy slip behaviour represent two different types of cyclically generated dislocation structures, which have a different stability towards cyclic deformation. The planar slip behaviour is marked by single slip up to highest load magnitudes. Although dislocations agglomerate locally, they are confined to single slip planes and the proportion of cross slip is neglectable. The dislocation structure can reach a certain saturation state, which will depend on the amplitude only. In case of the planar slip behaviour, the load-sequence is irrelevant. For the wavy slip behaviour the opposite is true. Low load magnitudes cause the generation of dislocation piles, dipoles and bundles. With increasing load magnitude and ongoning cyclic deformation persistent slip bands are formed and finally the cross slip transforms the 
ladder like structure of the persistent slip bands into a wall and sell like structure. Of course intermediate forms between planar and wavy slip are possible, as the tendency towards the wavy slip is considered to be dependent on the stacking fault energy. ${ }^{20,21,22}$ For the wavy slip character, the stress-strain behaviour depends on the load-time function. A comparison between the stress-strain curve from constant amplitude testing and the Incremental Step Test can be used to assess the slip behaviour macroscopically. Fig. 3 contains a schematic representation and the comparison of different stress-strain curves for a $42 \mathrm{CrMo} 4$ quenched and tempered steel.

a) schematic representation

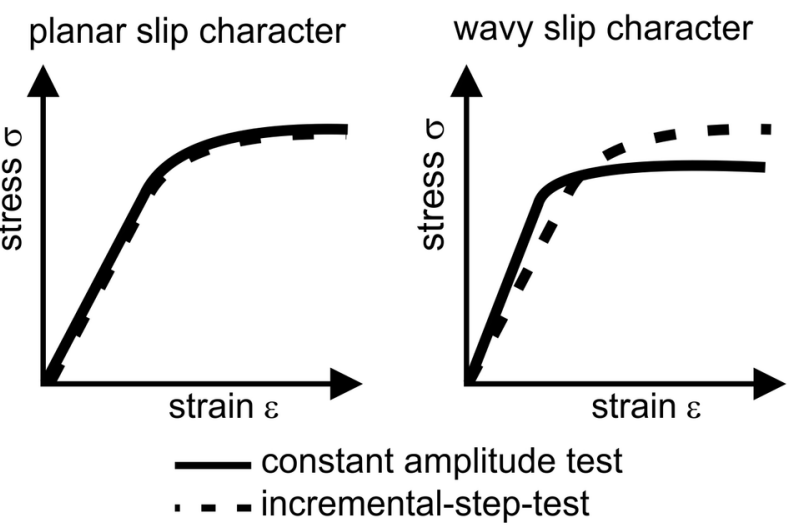

b) experimental results

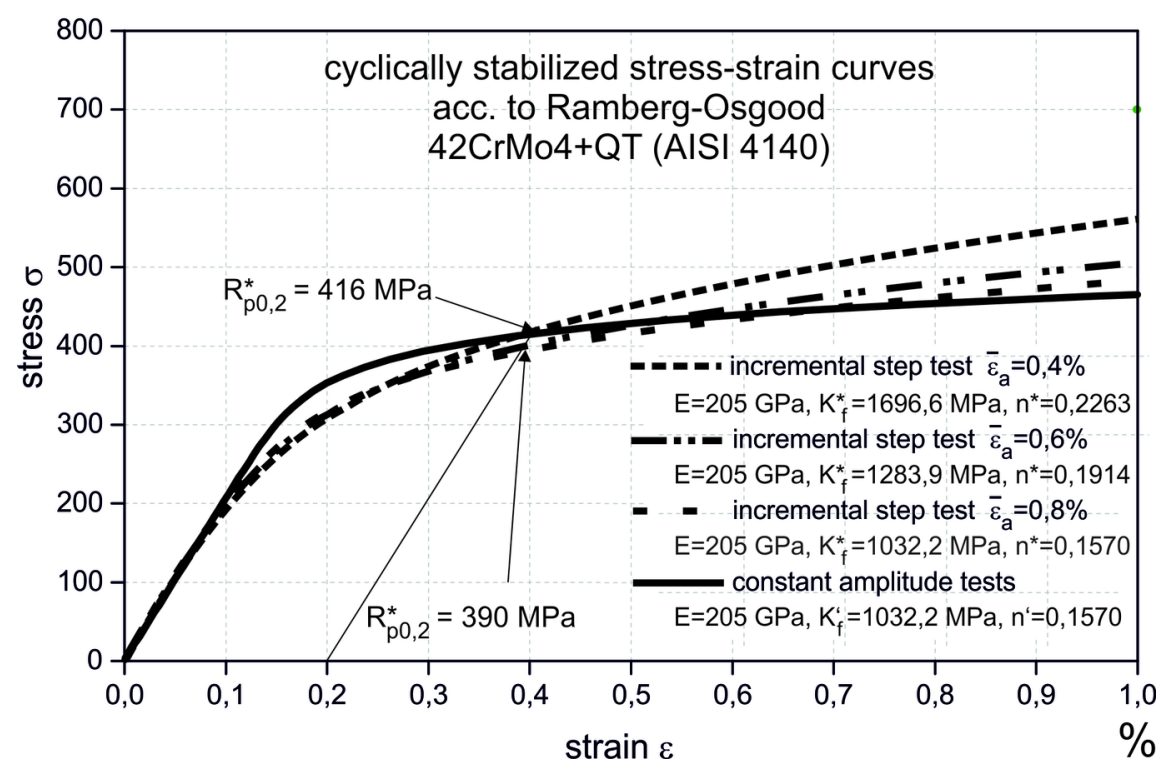

Fig. 3 a) Schematic representation of the influence of the slip character on the stress-strain behaviour, b) wavy slip behaviour of a $42 \mathrm{CrMo} 4+\mathrm{QT}$ heat treatable steel

The cyclically stablizied stress-strain curves at half the number of cycles to crack initiation already indicate, that the stabilization of the stress-strain behaviour depends on the load magnitude. This effect is related mainly to the generation of persistent disclocation arrangements. A comparison between the hystereses of the different blocks of the applied incremental step load sequence for a maximum total strain amplitude of $\varepsilon_{\mathrm{a}}=0,4 \%$ and $\varepsilon_{\mathrm{a}}=0,8 \%$ reveals, that the stabilization depends on the applied strain maximum, which is in 
accordance with the results under constant amplitude loading. For the incremental step test with a total strain amplitude of $\varepsilon_{\mathrm{a}}=0,4 \%$, the stress-strain path shows a decreasing but continuous cyclic softening from the first over the second to the third block. The stress-strain path of the test with $\varepsilon_{a}=0,8 \%$ strain amplitude contains a cyclic softening after the initial loading but stabilizes directly after the first block.
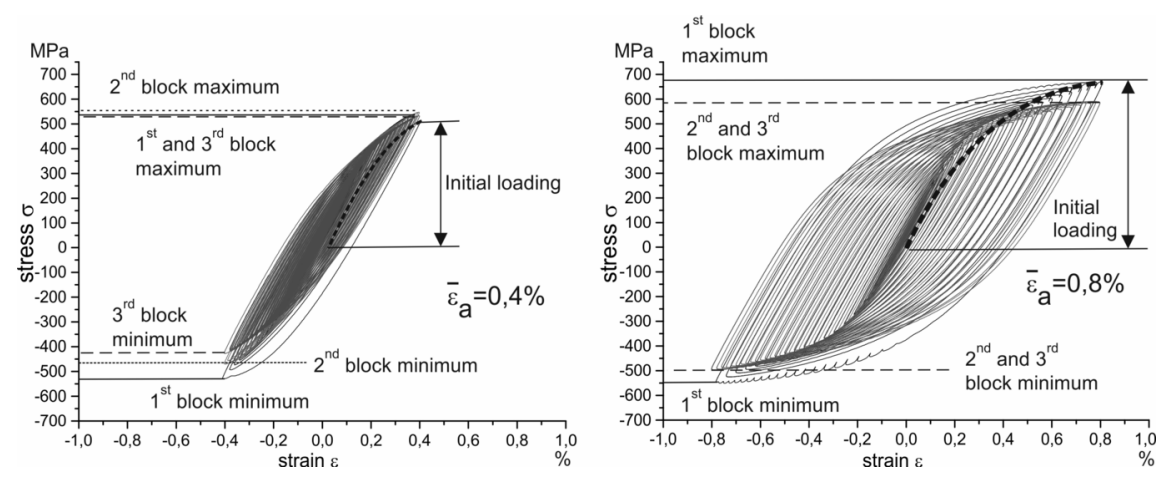

Fig. 4 Cyclical stabilization under incremental step loading

Different mathematical models have been proposed in order to implement the transient effects within the stress-strain behaviour, describing the evolution (translation, dilatation) of the yield surface over time either as time-dependent phenomenon including damping or strain-rate dependence. ${ }^{25}$ or as time-independent constitutional relation, linked to the stored plastic deformation, the cycle number or the damage. ${ }^{41,25,26}$ Latter also allow the discretization of the stress-strain behaviour over time and therefore enable a mathematically simple numerical treatment of time dependent effects.

\subsection{Time and location dependent thermal and mechanical load-time history}

The transient effects discussed before are usually assessed using homogeously loaded specimens for which the assumption of a homogeneous continuum may be valid. For load-time functions containing elasto-plastic loading, the change in strain respronse will depend on the load sequence. External loads like bending, torsional loads or thermal loadings but also features in the component geometry like notches or other abrupt changes in diameter or topology will cause a gradient stress field in the component. Depending on the load magnitude and the stress-gradient, the yield limit may be exceeded locally, while the rest of the cross-section remains in perfectly elastic condition.

\subsubsection{Load-sequence effects}

Two different types of load sequence effects may influence the local, damage relevant stress-strain state. During cyclic loading, the material behaviour is modified continuously. Some of the effects within the cyclic stress-strain behaviour are triggered by loads above the yield limit. Especially heattreated steels with martensitic microstructure will exhibit a significant cyclic softening, caused by martensite transformations, if the yield limit is exceeded. The changed strain response after the elasto-plastic loading will also correspond to a different fatigue life.

Consider the three different reconstructions of a load-time function from a very simple load spectrum, containing one load cycle above the initial (quasi-static) yield limit $\sigma_{\mathrm{y}}$ and four loads well below the initial yield limit, Fig. 5 a). If the cyclic softening is considered during the evaluation of the local stresses and strains, the strain response after the high load is increased, see. Fig. $5 \mathrm{~b}$ ). Due to the transient effects within the local strain-time function, the damage contribution of all three load-time functions is different $\left(\mathrm{D}_{1}<\mathrm{D}_{2}<\mathrm{D}_{3}\right)$. 


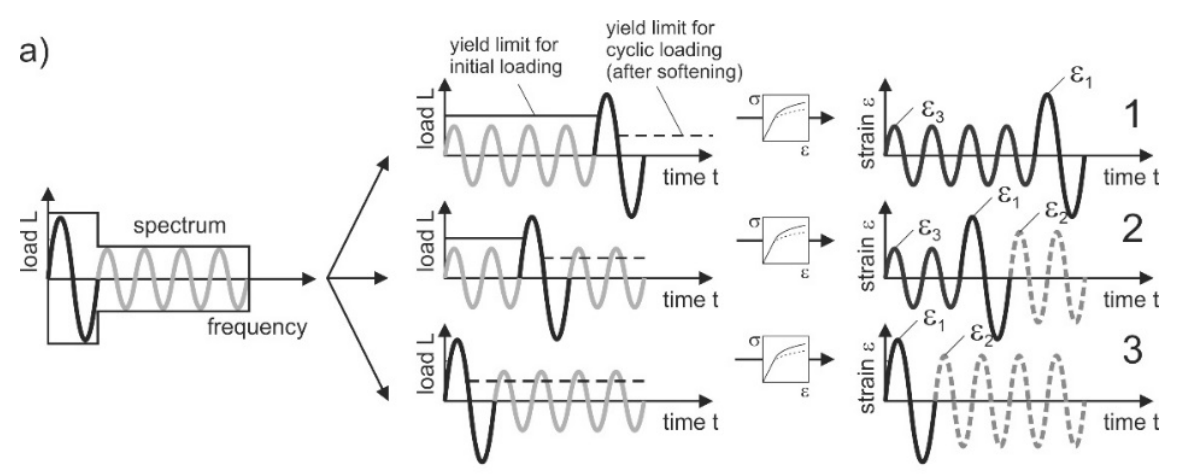

b)
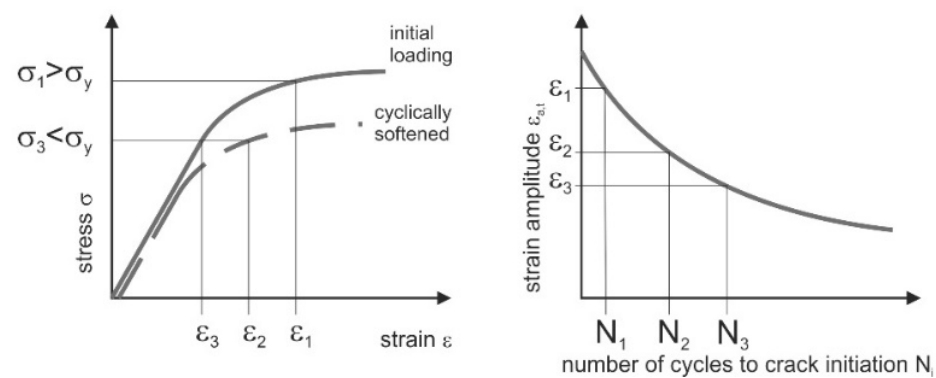

Fig. 5 a) Reconstruction of three different load-time functions and strain-time functions from a simple two level load spectrum, b) evaluating the strain response after cyclic softening and the corresponding fatigue lives

Another type of load sequence effect influences the local stress-strain state at stress concentrations. Due to the stress concentrations, resulting e.g. from notches, torsional or bending loading, also macroscopically elastic loading may cause locally limited plasticity. The boundary conditions of the highly stressed volume at the stress concentraion are governed by the stress gradient. If the notch root is deformed plastically during the load cycle, the remaining cross section will induce a stress, corresponding to the amount of plastic deformation on the highly stressed volume if the load is diminished completely. If the yield limit is not exceeded during the load-time function following the elasto-plastic loading, the residual stresses in the notch root are conserved and will shift the mean stress of the consecutive loading. Fig. 6 illustrates this effect schematically.

The cylindrical specimen (Fig. 6) with circumferential notch is loaded with a load time function containing a large load cycle at the beginning, during which the yield limit is exceeded locally in tension as well as in compression. After the unloading, a significant tensional stress remains locally, acting as a mean stress for the consecutive linear elastic loading. 


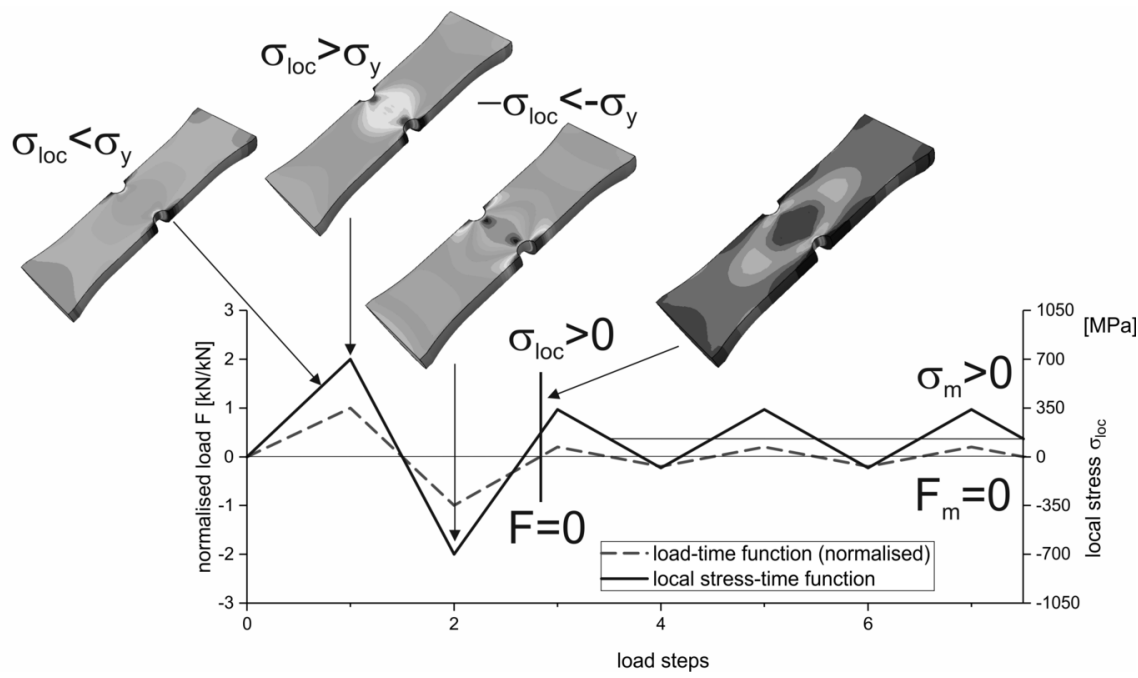

Fig. 6 Load sequence effect related to local plasticity at stress concentrations

Despite the question, if the mean stresses resulting from locally limited plasticity under cyclic loading remain stable or if they are annealed by relaxation effects during the consecutive loading, they will have a considerable impact on the calculated damage, if the calculation algorithm is defined properly.

\subsection{Manufacturing effects, anisotropy and localized material behaviour}

Although the manufacturing effects will be discussed using a forging process as example, they may be transferred also to other manufacturing processes leading to inhomogeneous property distributions as, for example, additive manufacturing or casting. A challenging task in this respect is to isolate the significant process parameters and their correlation to local microstructures and physical properties from the huge number of possible influencing factors. For the forged components assessed that were assessed in the project referred to in this paper, the process parameters of the forging were narrowed down to the local logarithmic strain and the temperature gradient.

For forged components made of steel with considerable sulfur content like precipitation hardening ferriticpearlitic steels (PHF), fibres of manganese sulfide inclusions can easily be made visible by etching, Figure 7. The sulfur content and the fibre orientation will have a considerable influence on the tensile, impact and

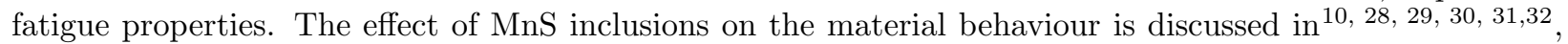
while ${ }^{33}$ puts a special emphasis on the key role of non-metallic inclusions on the fatigue behaviour in general. The maximum fatigue strength with respect to crack initiation and crack propagation lifetimes is achieved for a perfect alignment $\left(=0^{\circ}\right)$ of the fibre like forging texture with the load direction. The maximum reduction, accordingly, occurs at an orthogonal orientation $\left(=90^{\circ}\right)$ towards the load direction. 

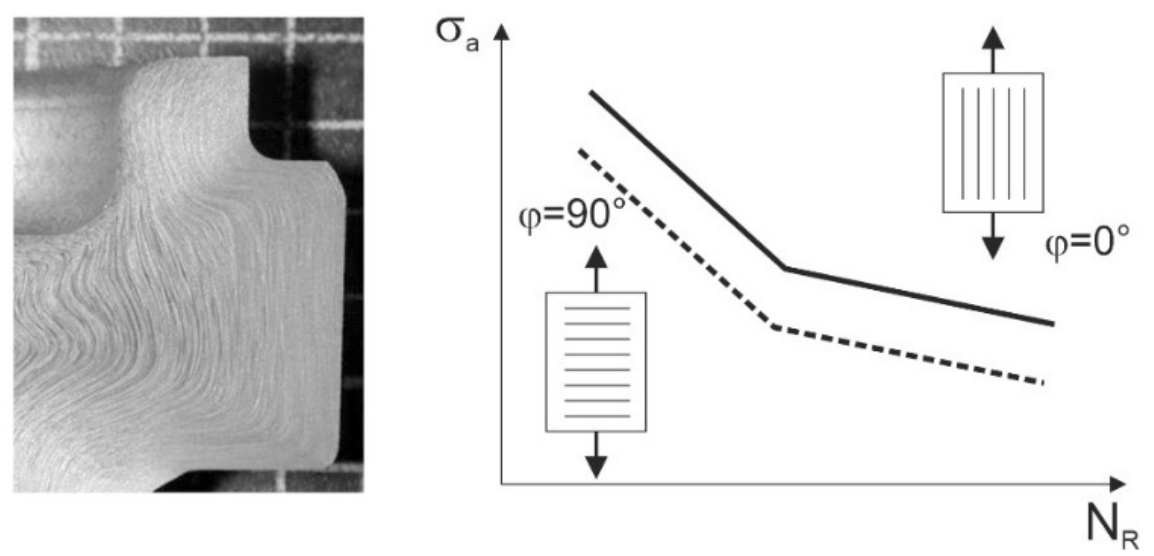

Fig. 7 Manganese Sulfide Fibres and schematic representation of the effect of anisotropy on the fatigue behaviour

For duplex strainless steels ${ }^{29}$ reports a maximum reduction in fatigue strength for $45^{\circ}$ orientation of the forging fibre towards the load direction, where the shear stress is at its maximum. For a EN AW-7475 and AW-7075, ${ }^{30}$ presents a comprehensive analysis of the effect of precipitate free zones at grain boundaries on the anisotropy of mechanical properties. For the EN AW-7475 and 7075, the fatigue strength does not drop continuously but has a local minimum at $=45^{\circ}$ orientation of the longitudinal axis of the forging texture towards the load direction and a global minimum at $=90^{\circ}$ for the EN AW-7075, while the fatigue strength of the EN AW-7475 at $=90^{\circ}$ is equal to the fatigue strength for perfect alignment of the fibres with the load direction $\left(=0^{\circ}\right)$.

In addition to the complex effect of anisotropy on the fatigue behaviour, the fatigue strength of forged steels may also depend on the forging process with respect to the local logarithmic strain and the cooling conditions. This leads to locally inhomogeneous cyclic material properties. Figure 8 illustrates the effect of the extraction position on the fatigue properties for a 38MnVS5 precipitation hardening ferritic-pearlitic steel, taken from a forged steering knuckle. The influence is pronounced especially for loads in the low cycle fatigue (LCF) regime, which usually have a strong impact on fatigue with respect to their amplitude and possible effects on the mean stress during variable amplitude loading.
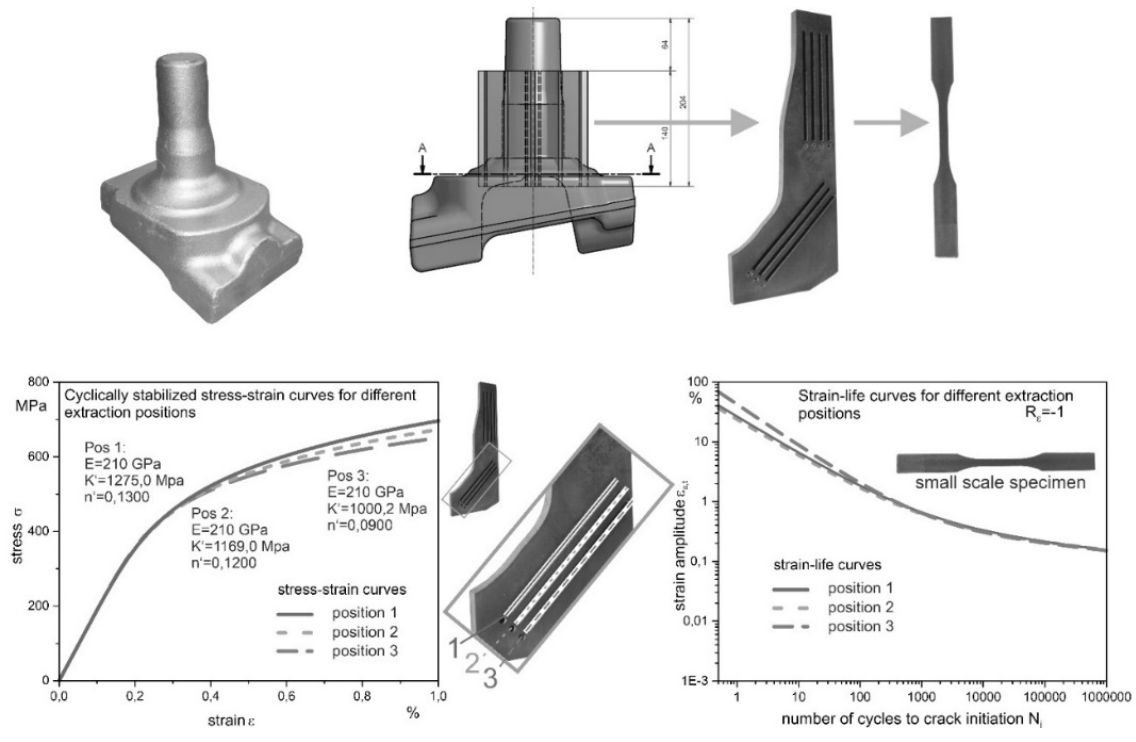
Fig. 8 Influence of the extraction position on the local fatigue and stress-strain behaviour

The influence of two different cooling conditions on the stress-strain behaviour is shown in Figure 9. For both cooling routes, the material was homogeneously heated to $1250^{\circ} \mathrm{C}$, forged and then cooled from the forging heat for the first cooling route by forced convection via blowing with fans and for the second cooling route by free convection. Cooling route 1 (forced convection) can be characterized by a $t_{8 / 5}$ time of $920 \mathrm{~s}$ while cooling route 2 has a $t_{8 / 5}$ time of $1120 \mathrm{~s}$.

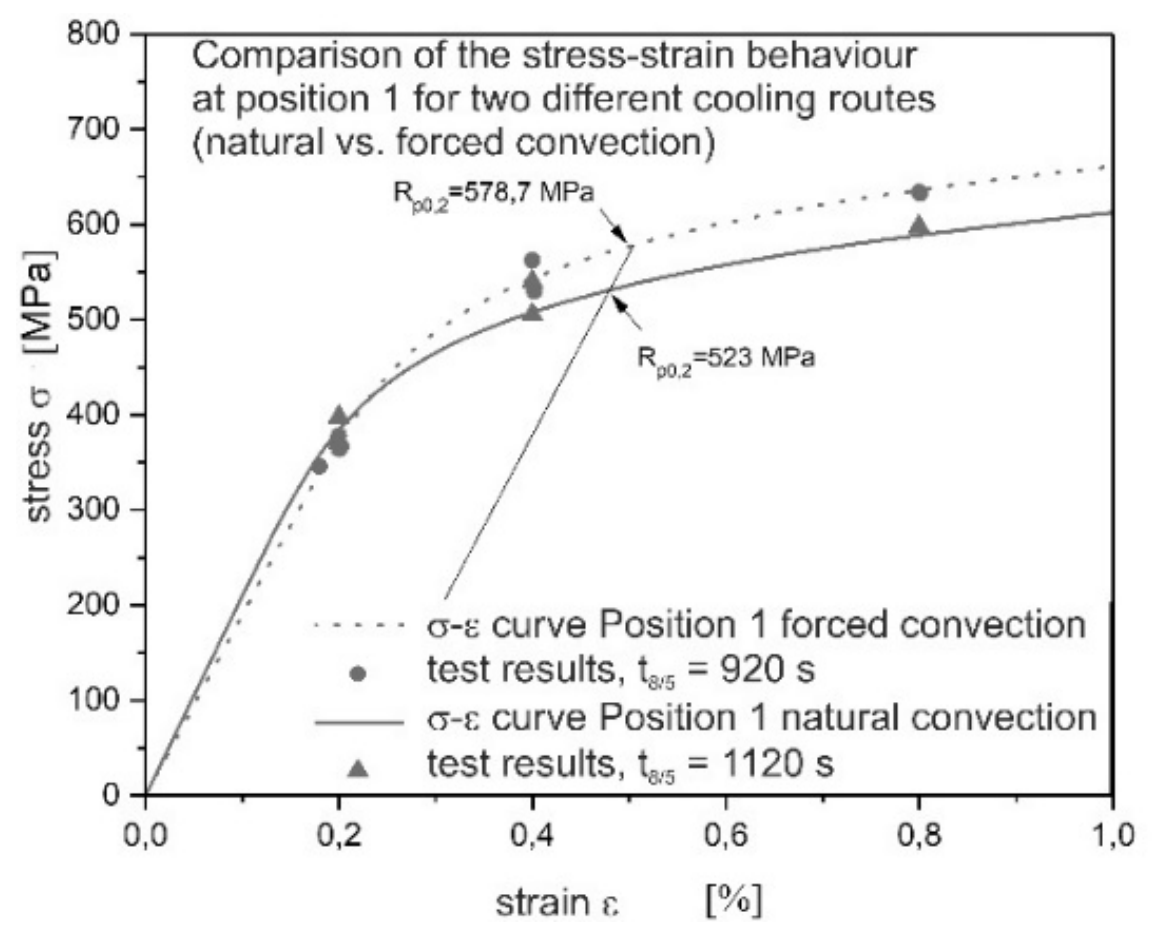

Fig. 9 Influence of the cooling condition on the cyclic stress-strain behaviour

In the state of the art, the local inhomogeneous material properties are usually not considered, or average values are used for the fatigue life estimation. As Fig. 10 shows, averaging all test results for the different extraction position results in a huge scatter of the fatigue lives around the S-N curve for a survival probability of $\mathrm{P}_{\mathrm{S}}=50 \%$. The effects of this scatter on the admissible local stresses will be discussed later with respect to the probabilistic safety factor. 


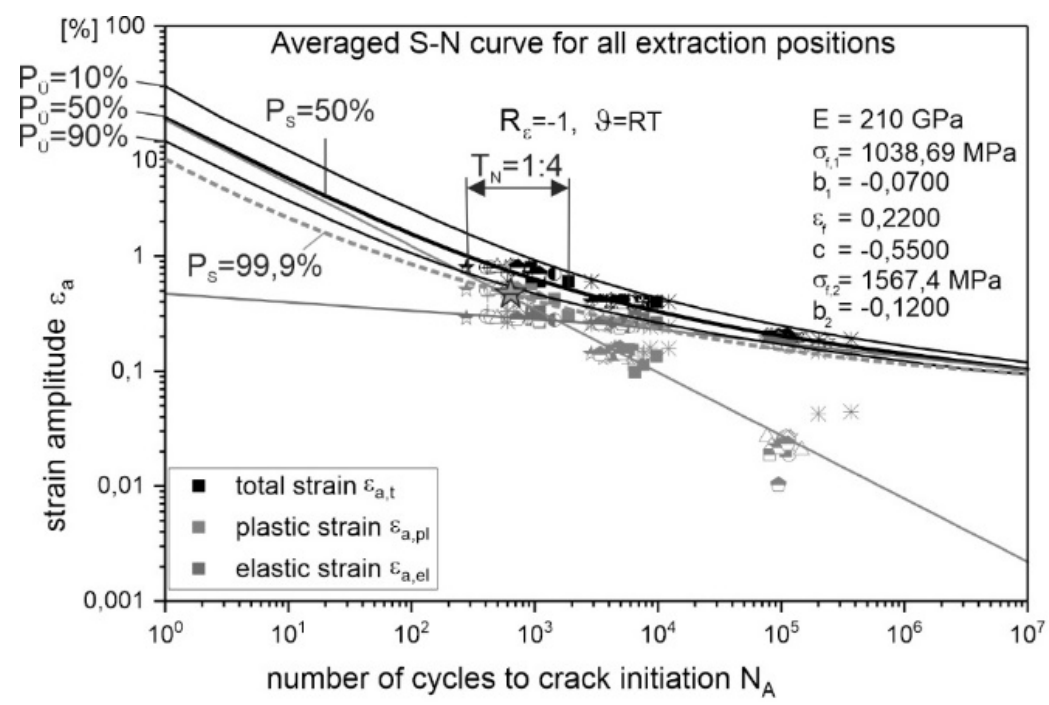

Fig. 10 Scatter of the fatigue lives for different extraction positions

\subsection{Size and geometry effects, stress gradient and notch effects}

The effects of the component size have to be interpreted on basis of all aforementioned influences, because the theoretical stress-gradient arising from simple mechanics will be superimposed by the gradient of the inhomogeneous material behaviour or localized plastic deformations. For fatigue approaches with linear elastic stress definition, those effects can only be considered implicitly using empirically defined correction factors for the fatigue limit. Perhaps the most comprehensive overview of different possible size effects was delivered by Kloos nearly 50 years ago. ${ }^{34}$ From a phenomenological point of view, the consideration of the mechanical, statistical, surface related and technological size effect during the fatigue life estimation is completely justified and has become state of the art in many guidelines implementing the nominal stress approach. On the other hand, it is not possible to assess the phenomenologically differentiated size effects separately. Many of the approaches consider an integral whole of all size effects. The main difference between the approaches is the consideration of the stress-gradient or the local stress-function. Approaches with implicit consideration of size effects, as, for example, the Stress Gradient Approach acc. to Siebel and Stieler ${ }^{35}$ will only work, if the notch support effect is characterized by a large number of tests. The Weakest-Link-Approach acc. to Weibull ${ }^{38}$, the Approach of the Highly Stressed Volume acc. to Kuguel ${ }^{36}$ or modified by Sonsino ${ }^{37}$ or the Similarity Criterion acc. to Kogaev-Serensen ${ }^{39}$ use correlations between the amount of highly stressed volume or area in comparison with selected reference specimens. Fatigue data of existing components may also be employed as data basis for the fatigue assessment.

\section{Deriving reliable design limits with material properties based on numerically assisted ex- perimentation}

In order to account for manufacturing process influences, the different size effects and also load sequence effects, the fatigue life algorithm in Figure 11 may be used. The mechanical, surface related and technological size effect are captured by the modelling of the local, process related and microstructure based material behaviour. The statistical size effect is implemented using the Weakest Link Approach acc. to Weibull ${ }^{39}$. 


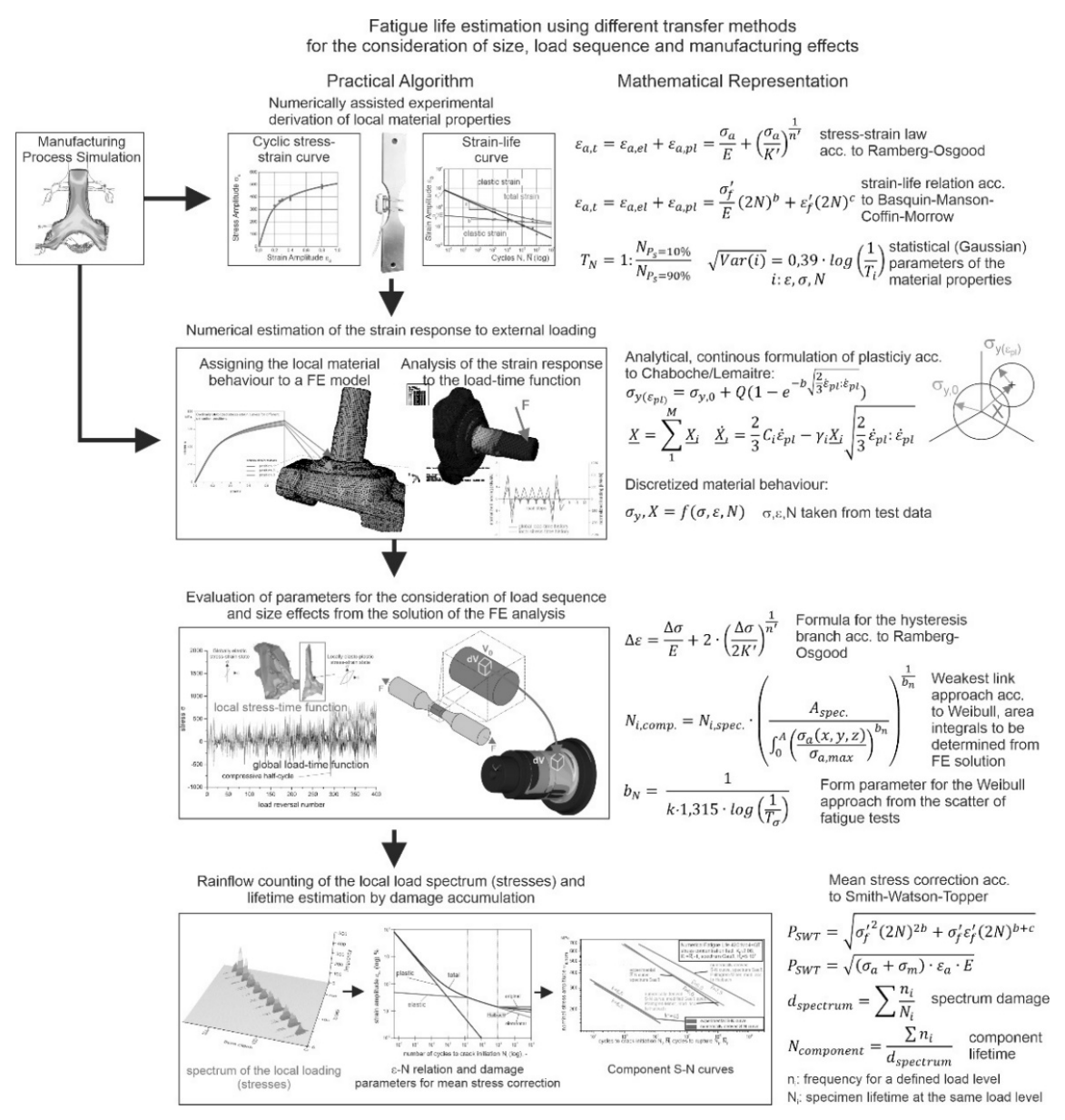

Fig. 11 Algorithm and mathematical representation of the fatigue life assessment with numerically assisted material characterisation

The algorithm starts with a numerically assisted material characterization using a process simulation for determining relevant process parameters and an experimental campaign with strain-controlled tests in order to derive the cyclic stress-strain curve acc. to Ramberg-Osgood ${ }^{41}$ and the strain-life curve acc. to BasquinManson-Coffin-Morrow. ${ }^{42,43,44,45}$ The results of the process simulation are also used to parametrize the numerical model for the calculation of the local strain response to external loading. The material model may either feature transient behaviour in a continuous formulation, for example acc. to Chaboche and Lemaitre ${ }^{46}$, or as stress-strain behaviour acc. to Ramberg-Osgood, in form of a discretized cycle or damage dependent formulation. In the following step, the external load-time function has to be translated into the function of local loads over time by an analysis of the local strain response to the external loading. The analysis of the strain response may be xecuted using a combination of finite element calculations and the application of the Neuber rule ${ }^{48,48}$ in order to increase the calculation speed to a level, that allows the estimation of the strain response also for large numbers of cycles to failure. From the numerical analysis of the local strain response, the parameters for the consideration of mean stresses by damage parameters, e.g. acc. to Smith-Watson-Topper ${ }^{49}$ or acc. to Bergmann ${ }^{50}$ are derived, accounting for mean stress changes resulting from load sequence effects. The parameters for the consideration of the statistical size effect acc. to Weibull, or with modifications acc. to Böhm ${ }^{51}$ for crack initiation from the surface, are also extracted and used to modify the S-N curve transfer the external load-time function of the service loads to the local stress-time function for a damage accumulation, for example acc. to Palmgren-Miner. ${ }^{53,53}$ 


\subsection{Numerically assisted derivation of the local material behaivour with respect to manufac- turing effects}

Metallic materials in forged components experience a large number of manufacturing steps from the first casting over different rolling or drawing processes up to the final heating, the forging and consecutive heat treatments. During all manufacturing steps, the microstructure of the material and the material properties are constantly being modified, resulting in property gradients throughout the component volume. It is obvious, that specimens extracted from the raw material, i.e. before the forging, will, due to the microstructural changes, exhibit a totally different fatigue behaviour than specimens extracted from the component. In order to achieve a good transferability from the specimen to the component geometry, those manufacturing processes have to be considered during the experimental campaign. In early product development stages, two different strategies may be applied in order to generate specimens with a representative material condition, Figure 12.

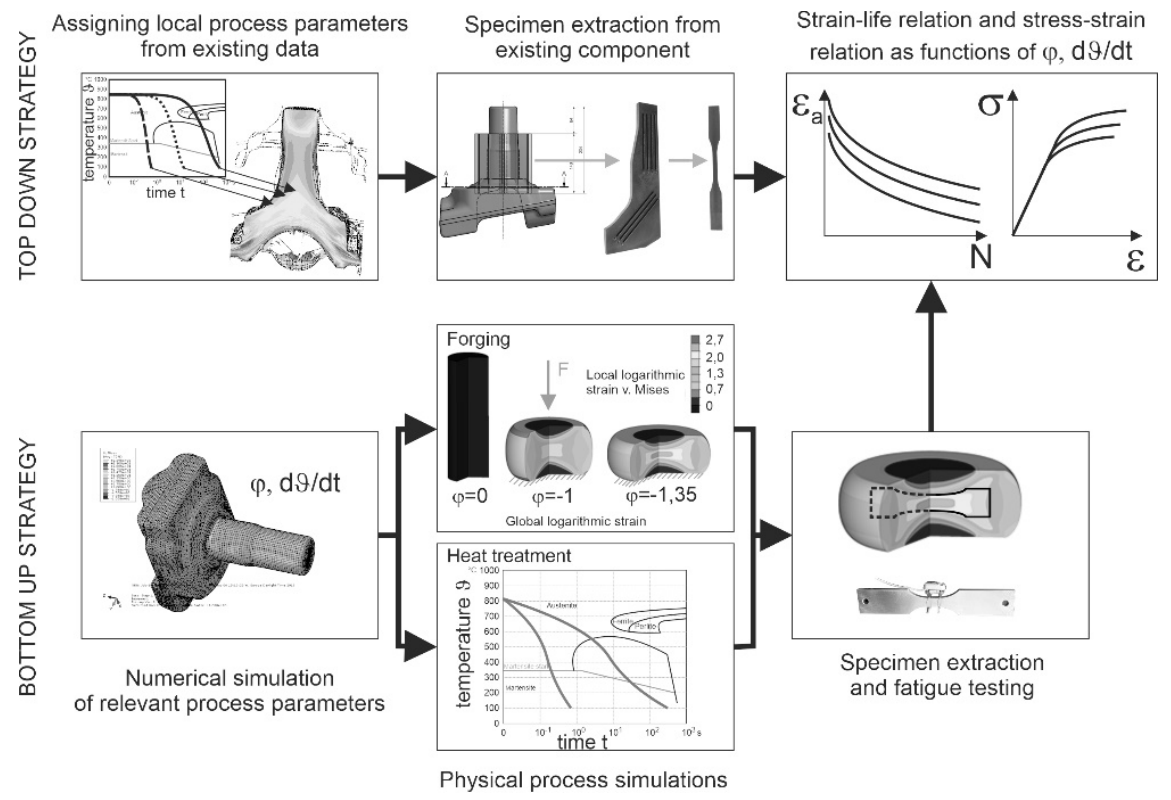

Fig. 12 Two different strategies for assessing the process influence on the material behaviour either based on existing components or physical process simulations in the laboratory environment

The bottom up strategy uses finite element simulations of the forging and cooling process, in order to define relevant logarithmic strains and temperature gradients over time. A physical process simulation combines a mechanical deformation with simultaneous heat treatment of the material in the initial state, i.e. before the manufacturing process. From the deformed and heat treated material, small scale specimens are extracted and put into fatigue testing, deriving the stress-strain behaviour and the fatigue properties for a very well defined material state. The top down strategy in Figure 12 starts with the extraction of material specimens from an existing component for which the process parameters of the manufacturing have to be known. In order to be able to interpret the fatigue test results with respect to the local logarithmic strain and the temperature gradient, a finite element simulation of the forging and the cooling process is required. Compared to the bottom up strategy, the combinations of logarithmic strains and temperature gradients are limited. This does not affect the transferability as long, as the material condition in the component to be assessed is comparable to the material condition of the component used for the derivation of the material properties.

For the selected precipitation hardening ferritic-pearlitic steel with $0.38 \mathrm{wt}-\%$ carbon content, both strategies were examined. For the top down strategy, a circumferential pattern was chosen for the extraction of 
a sufficient number of specimens for the experimental derivation of a strain-life curve acc. to Basquin, Manson, Coffin, Morrow and a stress-strain curve acc. to Ramberg-Osgood. With respect to the process parameters, the steering knuckles were manufactured on four different process routes with four respective cooling conditions, which were characterized by the local $t_{8 / 5}$ times, i. e. the transition time from 800 to $500^{\circ} \mathrm{C}$.

\subsection{Interpretation of the fatigue and stress-strain behaviour by numerical analysis of the pro- cess parameters}

For the Top down as well as for the bottom up strategy, a finite element simulation of the forging and cooling process is required in order to be able to interpret the test results with respect to the manufacturing influence. Figure 13 shows the results of the forging and cooling simulation.
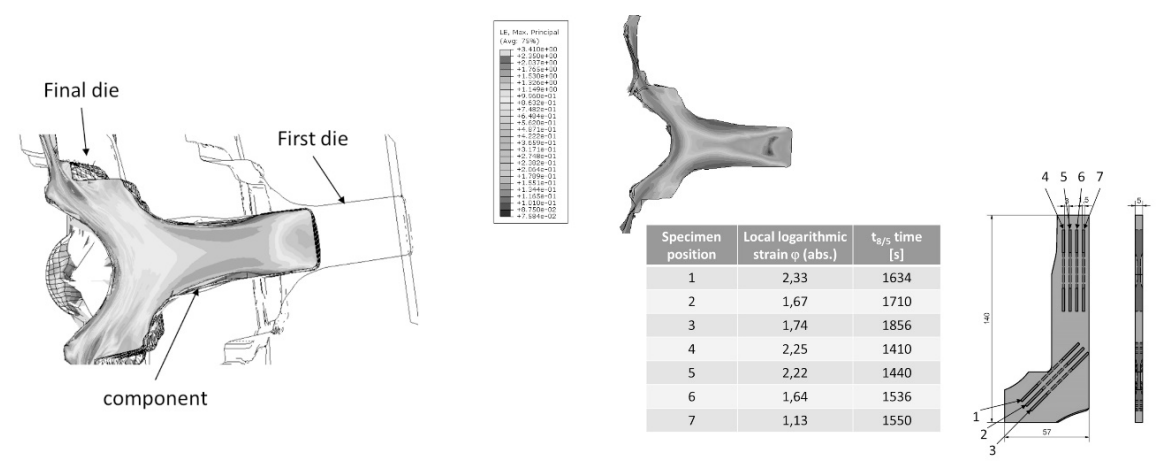

Fig. 13 Results of the forging and cooling simulation for the seven different extraction positions

With the help of the local logarithmic strain, a correlation analysis was carried out for the parameters of the strain-life curve acc. to Basquin-Manson-Coffin-Morrow as well as the stress-strain curve acc. to RambergOsgood. For the strain-life parameters, no correlation could be found. The stress-strain behaviour shows a correlation with the logarithmic strain for the cyclic hardening coefficient $\mathrm{K}^{\prime}$ as well as for the hardening exponent n', Figure 14.
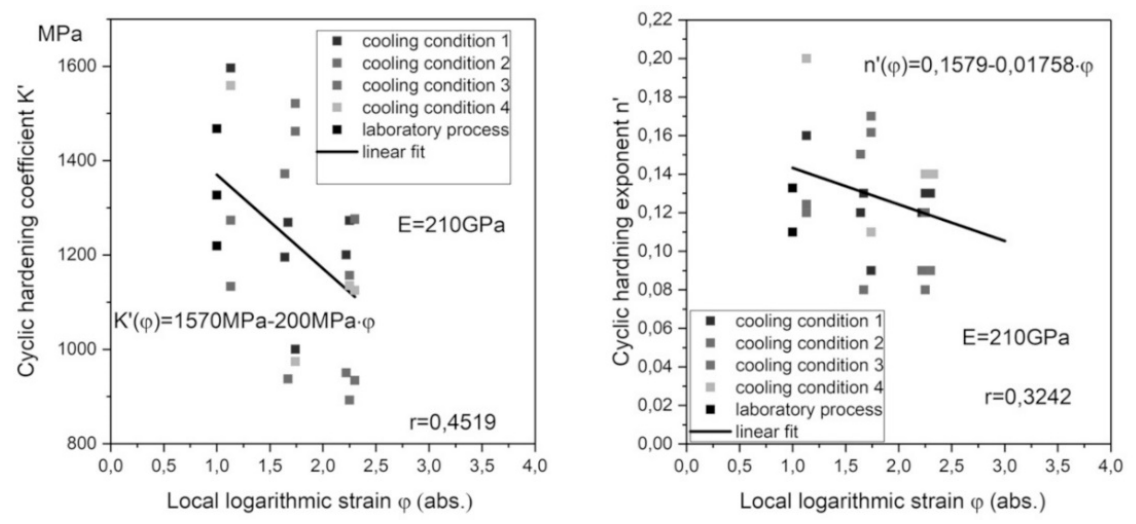

Fig. 14 Correlation between the cyclic hardening coefficient and exponent with the local logarithmic strain

Although differences in the strain-life relation are not as pronounced as in the stress-strain behaviour, they affect the fatigue life estimation by means of statistical influences. Figure 15 shows the scatter of all tests referring to a single approximation curve. Without consideration of the process parameters, all results for a range of the local logarithmic strain from $=1 \ldots 2.33$ put together yield a scatter band of $T_{N}=1: 4$, invoking a 
statistical safety factor of $\mathrm{j}_{\mathrm{N}}=1.37$ for a survival probability of $\mathrm{P}_{\mathrm{S}}=99.9 \%$. Selecting the points with respect to a defined local logarithmic strain of $=2.33$ severely reduces the scatter band to $T_{N}=1.41$ and the related safety factor to $\mathrm{j}_{\mathrm{N}}=1.19$ and increases the admissible stress for design optimizations.
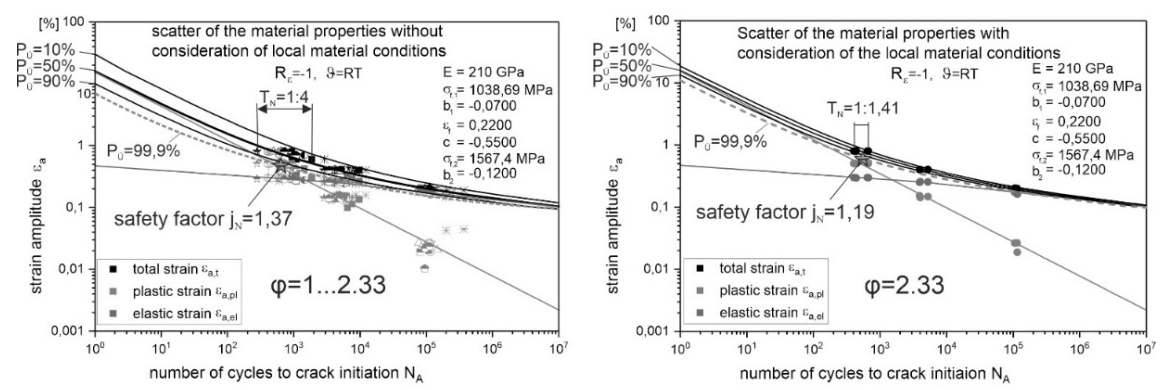

Fig. 15. Effect of the consideration of the process parameters on the scatter of test results and the required safety factor $\mathrm{j}_{\mathrm{N}}$

Figure 16 shows the comparison between the numerical and experimental fatigue lives of the investigated axle stub using the stress-strain relation for a local logarithmic strain of $=0$ (undeformed material) and a local logarithmic strain of $=2.33$. As the diagram shows, the calulatory results for the fatigue life are not conservative, if the stress-strain behaviour for the undeformed material is assumed. If the stress-strain relation is chosen according to the local process parameters, the numerical fatigue assessment provides conservative results in relation to the $\mathrm{P}_{\mathrm{S}}=50 \%$ line (dashed)

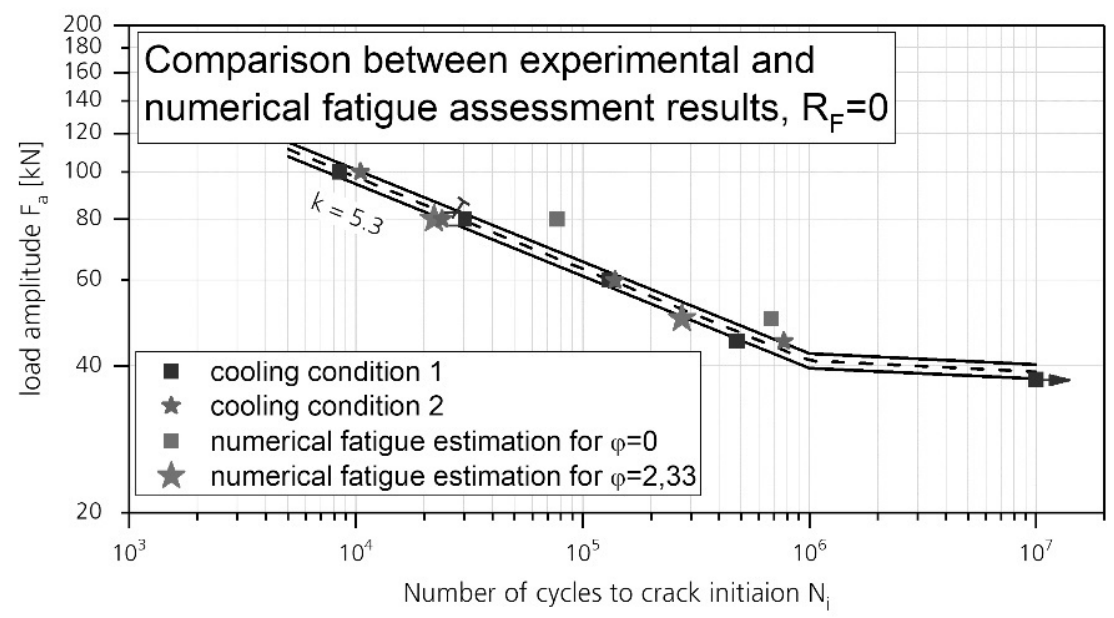

Fig. 16 Result of the fatigue assessment using process related material parameters

\section{Conclusion}

In order to derive design limits corresponding to a component S-N curve for forged components, a method including the process simulation of the forging process, a derivation of the fatigue and stress-strain properties by strain-controlled testing and a transfer to the component geometry using the Weakest Link Approach, an analysis of the strain response with finite element simulations and a consecutive fatigue estimation with 
damage parameters was proposed. For the investigated precipitation hardening ferritic-pearlitic steel, the analysis of the relation of selected process parameters has shown a correlation between the local logarithmic strain and the parameters of the stabilized cyclic stress-strain curves acc. to Ramberg-Osgood. An approximation by a linear fit could be established, allowing to choose a stress-strain behaviour according to an arbitrary local logarithmic strain, ranging from $=1 \ldots 3$. With the fatigue algorithm shown in Figure 11 and the approximation solution depicted in Figure 14, a sufficiently accurate fatigue life estimation with a conservative result in comparison with the experimental fatigue lives could be obtained. The fatigue life estimation with material parameters derived for the undeformed state (as delivered, before forging) did not yield conservative results. Therefore, it is recommended to include the process influence in the fatigue algorithm, in order to enable a reliable lightweight design with appropriate local stress limits.

\section{Acknowledgements}

The project AVIF A308 „Influence of the process parameters on fatigue behaviour of forged components“ is beeing funded by the charitable Foundation ,,Stiftung Stahlanwendungsforschung im Stifterverband für die Deutsche Wissenschaft e.V.". Detailed information about the project is available from Industrieverband Massivumformung e. V., Goldene Pforte 1, 58093 Hagen, Germany.

\section{References}

1 Krabiell, A., Reichel, U., Low-cycle fatigue properties of microalloyed medium carbon precipitation hardening steels in comparsion to quenched and tempered steels. steel res. , 1993; 64: 425-430

2 Küppers, M., Streicher, M., Herbert, A., Schönborn, S., Wisotzky, A., Betriebssichere Auslegung von Fahrwerksbauteilen aus AFP-Stahl am Beispiel eines NFZ-Achsschenkels, Mat. Test. , 2016; 58: 660-663

3 Wirths, V., Process route and cyclic material behavior of carbide free bainitic steels. 2016.

4 Murakami, M., Mura, T., Kobayashi, M., Change of Dislocation Structures and Macroscopic Conditions from Initial State to Fatigue Crack Nucleation, In: Fong JT, Fields RJ, eds. Basic questions in fatigue . ASTM STP 924, Philadelphia, ASTM. 1988; 39-63

5 Fatemi, A., Zoroufi, M., Fatigue Performance Evaluation of Forged versus Competing Manufacturing Process Technologies. Forg. Ind. Edu. and Res. Found. (FIERF) and Amer. Iron and Steel Inst. (AISI); 2004

6 Hell, M., Wagener, M., Estimation of Component Fatigue Lives under Service Load-Time Functions Using an Advanced Transfer Methodology for the Transition from Specimen to Component Related Material Behaviour. Proc. Struct. Int. 2019; 18 : 823-836

7 Wagener R., Hell M., Melz T. Anforderungen an ein Bemessungskonzept für zyklisch beanspruchte additiv gefertigte Bauteile. In: Richard H., Schramm B., Zipsner T., eds. Additive Fertigung von Bauteilen und Strukturen. Springer Vieweg, Wiesbaden; 2017

8 Scurria, M., Möller, M., Wagener, R., Bein, T., Effects of different heat treatments on the cyclic material behaviour of additively manufactured Inconel 718, Proc. Struct. Int. 2019; 18: 586-593

9 Wagener R., Hell M., Scurria M., Bein T., Deriving the Structural Fatigue Behavior of Additively Manufactured Components. In: The Minerals, Metals \& Materials Society, eds. TMS 2020 149th An. Meeting \& Exhib. Suppl. Proc. Cham, Springer; 2020

10 Exel, N., Kaufmann, H., Influence of manganese sulfide inclusions on the fatigue properties of AFP Steels. SCT 2011. Düsseldorf,Verlag Stahleisen; 2011: 51-57

11 Tomasella, A., Description of transient material behaviour under constant and variable amplitude loading for cold formed steels by linear flow splitting. Stuttgart, Fraunhofer Verlag; 2014

12 Schubert, R. ; Rie, K.-T.: Verfestigung, Fließfläche und Versetzungsstruktur bei Low-Cycle Fatigue. Mat.Wiss. u. Werkstofftechn. 1988; 19: 383-390 
13 J.L. Chaboche, Time independent constitutive theories for cyclic plasticity. Int. J. Plast. 1986; 2: 149-171 14 Ohno, D., Wang, J-D., Transformation of a nonlinear kinematic hardening rule to a multi-surface form under isothermal and nonisothermal conditions. Int. J. Plast. 1991; 7: 879-902

15 McDowell, D.L., Stress state dependence of cyclic ratchetting behavior of two rail steels. Int. J. Plast. 1995; 11: 397-421

16 Pilo, D., Reik, W., Mayr, P., Macherauch, E., Cyclic Induced Creep of a Plain Carbon Steel at Room Temperature. Fat. of Eng. Mat. and Struct. 1979; 1: 287-295

17 Christ, H. J., Wechselverformungsverhalten von Metallen. Berlin, Heidelberg, Springer. 1991

18 Polák, J., Man, J., Fatigue crack initiation - The role of point defects. Int. J. of Fat. 2014; 65: 18-27

19 Polák, J., Man, J., Mechanisms of extrusion and intrusion formation in fatigued crystalline materials. Mat. Sci. Eng. 2014; 15-24

20 Feltner, C.E., Laird, C., The role of slip character in steady state cyclic stress-strain behavior. Trans. TMS-AIME1969. 1969; 245: 1372-1373

21 Laufer, E. E., Roberts, W. N., Dislocations and Persistent Slip Bands in Fatigued Copper. Phil. Mag. 1966; 127: 65-78

22 Mughrabi, H., Ackermann, F., Herz, K., Persistent Slipbands in Fatigued Face-Centered and BodyCentered Cubic Metals. In: Long, J., eds. Fatigue Mechanisms. ASTM STP 675. Philadelphia, ASTM; 1979: 69-97

23 Hunsche, A., Neumann, P., Crack Nucleation in Persistent Slipbands. In: Fong JT, Fields RJ, eds. Basic questions in fatigue. ASTM STP 924. Philadelphia, ASTM. 1988; 26-38

24 Roberts, C., Greenough, A. P., Slip Line and Dislocation Structures in Fatigued Copper. Phil. Mag. 1965; 12: $81-87$

25 François, D., Pineau, A., Zaoui, A., Mechanical Behaviour of Materials Volume II: Viscoplasticity, Damage, Fracture and Contact Mechanics. Alphen aan den Rijn, Kluwer Academic Publishers. 1993

26 Hell, M., Wagener, R., Kaufmann, H., Melz, T., (2017) Effect of the material modeling and the experimental material characterisation on fatigue life estimation within strain-based fatigue assessment approaches. Proc. 7th Eng. Int. Soc. Conf. Durabil. Fat.Cambridge. 2017

27 Möller, B. Integral treatment of butt joints for the fatigue life assessment in the low cycle fatigue regime. Weld. World. 2021; 65: 275-288

28 Cyril, N., Fatemi, A., and Cryderman, B., Effects of Sulfur Level and Anisotropy of Sulfide Inclusions on Tensile, Impact, and Fatigue Properties of SAE 4140 Steel. SAE Int. J. Mater. Manf. 2009; 1(1): 218-227

29 Pessard, E., Morel, F., Morel, A., The anisotropic fatigue behavior of forged steel. Adv. Eng. Mat. 2009; 11(9): 732-735

30 Temmel, C., Karlsson, B., Ingesten, N.G., Met. Mat. Trans.2008; 39A: 1132-1144

31 Temmel, C., Karlsson, B., Ingesten, N.G., Fat. Fract. Eng. Mat. Struct. 2008; 31: 466-477

32 Hayne, M.L., Anderson, P.I., Findley, K.O., Effect of Microstructural Banding on the Fatigue Behavior of Induction-Hardened 4140 Steel. Metall. Mater. Trans. 2013; A44 3428-3433

33 Mateo, A., Llanes, L., Akdut, N., Stolarz, J., Anglada, M., Anisotropy effects on the fatigue behaviour of rolled duplex stainless steels.

Int. J. Fat. 2003; 25: 481-488 
34 Kloos, K.-H., Einfluss des Oberflächenzustandes und der Probengröße auf die Schwingfestigkeitseigenschaften. VDI-Berichte. 1976; 268: 63-76

35 Siebel, E., Stieler, M., Ungleichförmige Spannungsverteilung bei schwingender Beanspruchung. VDI-Z. 1955; 97(5): 121-126

36 Kuguel, R., A Relation between Theoretical Stress Concentration Factor and Fatigue Notch Factor Deduced From the Concept of Highly Stressed Volume., Proc. ASTM. 1961; 61: 732-744

37 Sonsino, C.M., Zur Bewertung des Schwingfestigkeitsverhaltens von Bauteilen mit Hilfe örtlicher Beanspruchungen. Konstruktion.1993; 45: 25-33

38 Weibull, W., A Statistical Theory of The Strength of Materials.Ing. Hand. 151. 1939

39 Hänel, B., Wirthgen, G., Die Berechnung der Dauerfestigkeit nach dem Verfahren von Kogaev und Serensen. IfL-Mitt. 1981; 20: 65-74,

40 Hell, M., Wagener, R., Kaufmann, H., Melz, T., Fatigue Life Design of Components under Variable Amplitude

Loading with Respect to Cyclic Material Behaviour. Proc. Eng. 2015; 101: 194 - 202

41 Ramberg W., Osgood, WR., Description of Stress-Strain Curves by Three Parameters. NACA Technical Note 902 . 1943

42 Basquin, OH., The exponential law of endurance tests. ASTM Proceedings . 1910; 10: 625-30

43 Manson, SS. Fatigue: A complex subject - Some simple approximations.Exp. Mech. 1965; 5(7):193-226

44 Coffin LA. A study of the effects of cyclic thermal stresses on a ductile metal. Trans. ASME . 1954; 76: 931-50.

45 Morrow, JD. Cyclic Plastic strain Energy and Fatigue of Metals. In: Lazan, B., ed., Internal Friction, Damping and Cyclic Plasticity.ASTM STP 378. Philadelphia, ASTM. 1965 ; 45-87

46 Lemaitre, J., Chaboche, J., Mechanics of Solid Materials . Cambridge: Cambridge University Press. 1990 47 Neuber H., Über die Berücksichtigung der Spannungskonzentration bei Festigkeitsberechnungen. Konstruktion. 1968; 20(7): 245-51

48 Neuber H. Kerbspannungslehre. Springer Verlag, Berlin. 2001

49 Smith, KN., Watson, P., Topper, TH., A Stress-Strain Function for Fatigue of Metals. J. Mat. 1970; 5: $767-78$

50 Bergmann, J. W., Zur Betriebsfestigkeitsbemessung gekerbter Bauteile auf der Grundlage der örtlichen Beanspruchungen . Darmstadt, Institut für Stahlbau und Werkstoffmechanik der TU Darmstadt. 1983

51 Böhm, J., Heckel, K., Die Vorhersage der Dauerschwingfesigkeit unter Berücksichtigung des statistischen Größeneinflusses. Z. Werkstofft. 1982; 13: 120-128

52 Palmgren, AP., Die Lebensdauer von Kugellagern. VDI Z. 1924; 68(14): 339-41

53 Miner, MA. Cumulative Damage in Fatigue. J. Appl. Mech. 1945; 12(3): A159-64.

54 Hell, M., Wagener, R., Estimation of Component Fatigue Lives under Service Load-Time Functions Using an Advanced Transfer Methodology for the Transition from Specimen to Component Related Material Behaviour. Proc. Struct. Int.,

2019 ; 18: 823-836

Highlights: 
- New findings regarding manufacturing influences on the fatigue behaviour of PHF steels - A novel combination of manufacturing simulations and fatigue testing

- Practical approximations for manufacturing influences on assessed fatigue lives

- Reduction of required statistical safety factors and improvement of fatigue assessment 